OPEN ACCESS

Edited by:

Qifu Li,

First Affiliated Hospital of Chongqing

Medical University, China

Reviewed by:

Heike Muenzberg-Gruening,

Pennington Biomedical Research

Center, United States

P Trayhurn,

University of Liverpool,

United Kingdom

*Correspondence:

Per Svenningsen

psvenningsen@health.sdu.dk

Specialty section:

This article was submitted to

Translational Endocrinology,

a section of the journa

Frontiers in Endocrinology

Received: 16 March 2021

Accepted: 22 July 2021

Published: 12 August 2021

Citation:

Sabaratnam $R$ and Svenningsen $P$

(2021) Adipocyte-Endothelium

Crosstalk in Obesity.

Front. Endocrinol. 12:681290.

doi: 10.3389/fendo.2021.681290

\section{Adipocyte-Endothelium Crosstalk in Obesity}

\author{
Rugivan Sabaratnam ${ }^{1,2,3}$ and Per Svenningsen ${ }^{3 *}$ \\ 1 Steno Diabetes Center Odense, Odense University Hospital, Odense, Denmark, 2 Section of Molecular Diabetes and \\ Metabolism, Department of Clinical Research, University of Southern Denmark, Odense, Denmark, ${ }^{3}$ Department of Molecular \\ Medicine, Cardiovascular and Renal Research, University of Southern Denmark, Odense, Denmark
}

Obesity is characterized by pathological adipose tissue (AT) expansion. While healthy AT expansion enhances systemic insulin sensitivity, unhealthy AT expansion through increased adipocyte size is associated with insulin resistance, fibrosis, hypoxia, and reduced adipose-derived adiponectin secretion. The mechanisms causing the unhealthy AT expansion are not fully elucidated; yet, dysregulated crosstalk between cells within the AT is an important contributor. Evidence from animal and human studies suggests a crucial role of the crosstalk between vascular endothelium (the innermost cell type in blood vessels) and adipocytes for metabolic homeostasis. Arterial endothelial cells are directly involved in maintaining normal organ functions through local blood flow regulation. The endothelial-dependent regulation of blood flow in AT is hampered in obesity, which negatively affects the adipocyte. Moreover, endothelial cells secrete extracellular vesicles (EVs) that target adipocytes in vivo. The endothelial EVs secretion is hampered in obesity and may be affected by the adipocyte-derived adipokine adiponectin. Adiponectin targets the vascular endothelium, eliciting organ-protective functions through binding to Tcadherin. The reduced obesity-induced adiponectin binding of T-cadherin reduces endothelial EV secretion. This affects endothelial health and cell-cell communication between AT cells and distant organs, influencing systemic energy homeostasis. This review focuses on the current understanding of endothelial and adipocyte crosstalk. We will discuss how obesity changes the AT environment and how these changes contribute to obesity-associated metabolic disease in humans. Particularly, we will describe and discuss the EV-dependent communication and regulation between adipocytes, adiponectin, and the endothelial cells regulating systemic energy homeostasis in health and metabolic disease in humans.

Keywords: adipose tissue, endothelial cells, hypoxia, extracellular vesicles, endocrine, nitric oxide

\section{INTRODUCTION}

Obesity, defined as excessive fat accumulation, is a worldwide epidemic accompanied by an increased risk of developing cardiovascular diseases (CVDs), certain types of cancers, Alzheimer's disease, non-alcoholic fatty liver disease, and type 2 diabetes mellitus (T2D) (1). The link between the increased disease risks and excessive fat accumulation is not completely 
understood but appears to rely on impaired white adipose tissue (WAT) function. WAT functions as an energy buffer that stores and releases energy (2); however, WAT is also an essential endocrine organ and plays a key role in regulating systemic glucose and energy metabolism by secreting an array of adipokines, including leptin and adiponectin (3). WAT is recognized as a highly dynamic and heterogeneous organ, and the adaptation to expanding WAT requires coordinated actions of multiple cell types to ensure a healthy adipocyte environment.

The WAT adapts to the excessive energy intake through two mechanisms 1) an increase in adipocyte number (hyperplasia) and/or 2) size (hypertrophy) (4). The hyperplastic WAT expansion is characterized by the formation of new adipocytes from adipose progenitor cells, which is associated with enhanced systemic insulin sensitivity. Hypertrophic WAT expansion is, on the other hand, characterized by insulin resistance, dysfunctional prolipolytic action, increased inflammation, fibrosis, and altered adipokine secretion profile, including decreased adiponectin levels $(4,5)$. Unhealthy WAT expansion is the sine qua non of metabolic unhealthy obesity, causing ectopic lipid accumulation in peripheral tissues such as the liver and skeletal muscle (4). The molecular mechanisms underlying the transition from a healthy WAT to an unhealthy pathological expansion are yet to be elucidated. Here, we will review and summarize our current understanding of the crosstalk between the adipocytes and the arterial endothelial cells within the WAT and how this communication potentially regulates systemic energy homeostasis in metabolic disorders.

\section{THE ADIPOSE TISSUE MICROENVIRONMENT}

Adipose tissue is a heterogenous cell population and contains, besides adipocytes, fibroblasts, stem cells, immune cells, and endothelial cells, and their intercellular crosstalk is crucial for the microenvironment (6). There is substantial evidence, mainly from animal studies, that hypertrophic obesity is associated with low oxygen tension in AT and increased expression of hypoxia-response genes (7), including the master regulator of hypoxia, hypoxia-inducible factor 1 (HIF1) (8). In primary adipocytes and macrophages from lean mice, hypoxia increases expression of inflammatory markers such as TNF- $\alpha$, IL-1, IL-6, and TGF- $\beta$, chemokine (MIF), extracellular enzyme (MMP9), and macrophage markers (CD11 and F4/80) (7). The effect of hypoxia on the expression of adipokines in human adipocytes revealed increased gene expression levels of FIAF/angiopoietinlike protein 4, IL-6, leptin, MIF, PAI-1 and vascular endothelial growth factor (VEGF) (9). In 3T3-L1 cells, the promoter activity of NFkappaB and TNF- $\alpha$ was activated by hypoxia, causing reduced adiponectin promoter activity (7). Adipocyte-specific knockout of Hif1 $\beta$ - the obligate partner of hypoxia-inducible factors (Hifla, Hif2a, and Hif3a) - reduced weight gain relative to wild-type controls and showed decreased high-fat diet (HFD)induced obesity and glucose intolerance (10), indicating that the adipocyte-response to hypoxia is negative.
Oxygen tension in human WAT is challenging to measure, and the measured levels between lean and obese are dependent on the techniques used (11). Goossens et al. found that oxygen tension in WAT was higher in obese, and the obese subjects had lower WAT oxygen consumption (12). On the other hand, Pasarica et al. found that obesity was associated with lower WAT partial $\mathrm{O}_{2}$ pressure, and obese subjects had a lower capillary density and decreased gene expression of WAT VEGF (13). Despite these differences in these two studies, the obese subjects had insulin resistance, high expression of inflammatory cell markers, and lower WAT capillarization $(12,13)$. Cifarelli et al. reported that the human AT expansion in obesity is associated with reduced AT pO2, which contributes to increased AT HIF-1 $\alpha$ expression (14). These alterations decrease the branched-chain amino acid (BCCA) catabolism and increase the AT inflammation and fibrosis. Ultimately, this leads to an increase in circulating BCAAs and PAI-1 causing systemic insulin resistance (14). Very recently, Todorčević et al. demonstrated that markers of subcutaneous AT hypoxia are elevated in severely obese patients with obesity hypoventilation syndrome but not in moderately obese individuals, suggesting that in moderate obesity, AT dysfunction may not be driven by hypoxia (15).

Capillarization is endothelial-dependent, and blockage of vascularization in WAT causes unhealthy tissue expansion, enhanced inflammation and fibrosis, leading to systemic insulin-resistance (16-21). On the other hand, stimulation of angiogenesis results in healthy WAT expansion even during HFD-feeding and is associated with maintained insulinsensitivity (16-21). Collectively, it appears that the interplay between AT cells is crucial for metabolic homeostasis and hampered endothelial-dependent regulation of WAT blood flow affects AT plasticity.

Using single-cell RNA-sequencing (scRNA-seq), it has become possible to perform large-scale transcript profiling of heterogeneous cell populations obtained from WAT from mice $(22,23)$ and humans (24). scRNA-seq of the stromal vascular fractions from visceral and subcutaneous WAT samples from obese patients undergoing bariatric surgery classified the cells into three subpopulations: 1) progenitors or stem cells (55\%), 2) immune cells (37\%), and 3) endothelial cells (8\%) (24). Interestingly, endothelial cells could furthermore be divided into three types of endothelial cells (EC1-3). EC1 cells express genes (FABP4, LGALS1, RBP7, GPX3, and CD36) involved in lipid handling machinery, while EC2 cells had pronounced expression of canonical endothelial markers (ACKR1, SELE, TM4SF1, VCAM1, TMEM173, PLVAP, ICAM1, PECAM1, VWF, ADAMTS9, and TFPI). EC3 cells were highly enriched in LYVE1 expression, which is a marker of lymphatic endothelial cells (24). The lymphatic endothelial cells were predominantly present in visceral WAT samples (24). Although it is beyond the present review's scope, it is worth mentioning that lymphatic vessels (25) and immune cells (26) have been shown to contribute to unhealthy obesity. For example, lymphatic vasculature dysfunction was associated with an adult-onset obesity phenotype (27), and ablation of macrophages, through 
transgenic expression of diphtheria-toxin receptor under control of CD11c promoter, in mice fed an HFD normalized insulin sensitivity and reduction in local and systemic inflammation markers (28). Nonetheless, the vascular endothelial cells, representing only a minor fraction of the total cell population, have prominent physiological and biological roles in health and metabolic disease. Importantly, endothelial dysfunction is an early vascular abnormality in metabolic disorders, and emerging evidence supports a critical role of endothelial cells in the development of metabolic disorders.

\section{VASCULAR ENDOTHELIAL CELLS ARE CRUCIAL FOR WHOLE- BODY METABOLISM}

The vascular endothelial cells are the inner most cell type of arteries, veins and capillaries. The vascular endothelial cell function sustains organ homeostasis by regulating vascular tone, recruitment of blood cells, exchanging tissue factors, forming new blood vessels, and providing organ-specific barrier function (29). Unlike other healthy cell types, endothelial cells generate most of their ATP from glycolysis (30). Endothelial cells have an insulin-independent glucose uptake through glucose transporter 1 (GLUT1) (31), and hyperglycemia, an associated consequence of obesity, is likely to increase the endothelial cells glucose concentration, which in itself is enough to cause oxidative stress and endothelial dysfunction (32). Although the endothelial glucose uptake is insulin-independent, impaired insulin signaling in endothelial cells can affect systemic insulin sensitivity. HFD fed mice have a reduction in insulin receptor substrate (Irs) 1 and 2 in the endothelial cells, and endothelial-specific knockout of Irs2 impaired insulin-induced glucose uptake in skeletal muscle (33). A vital function of the endothelium is to induce relaxation of the underlying vascular smooth muscle cells through the release of nitric oxide (NO) and thereby increase blood flow. The endothelium NO is generated primarily by the endothelial NO synthase (eNOS), and in endothelial-specific Irs2 knockout mice, the insulin-induced eNOS activation by phosphorylation was blocked, likely through reduced phosphoAkt (33). eNOS-phosphorylation was restored by the stable prostaglandin I2 analog beraprost sodium, which reestablished glucose uptake by the skeletal muscle in the endothelial Irs2 knockouts on a normal and HFD (33). Moreover, the antidiabetic drug metformin, which enhances whole-body insulin sensitivity, improves endothelial-dependent relaxation (34), indicating a critical role for endothelial blood flow regulation for the $\mathrm{AT}$.

\section{ENDOTHELIAL-DEPENDENT BLOOD FLOW}

The endothelial-dependent vasodilatation is compromised in metabolic diseases, including obesity, and aging and is linked to reduced release of NO (35), increased oxidative stress (36), decreased endothelium-dependent hyperpolarization (37), and upregulation of released endothelium-derived contracting factors (38), which in combination results in reduced relaxation to vasodilatory substances such as acetylcholine in ex vivo arterial preparations. In humans and mice, increased body weight is associated with decreased endothelial-dependent vasodilatory in response to vasodilatory substances (39-43). Ingestion of food increases adipose tissue blood flow (ATBF) (44), and an oral glucose load increased ATBF in lean but not in obese subjects (12). The mediators responsible for this fast adjustment of ATBF are unknown, but intervention studies have provided evidence for the factors involved. Although increased glucose levels enhance plasma insulin levels, insulin micro infusion did not directly affect ATBF in humans (45). However, the ATBF increase correlated with changes in plasma norepinephrine (45). Plasma norepinephrine is likely to derive from spill over of sympathetic activity in muscle and AT (46). Norepinephrine is an endothelium-dependent arterial vasodilator (47) and high $\mathrm{ATBF}$ responding subjects had greater changes in plasma norepinephrine (44). Moreover, pharmacological intervention studies in humans have demonstrated that ATBF relies on the endothelial NO system $(11,48,49)$, indicating that sympathetic activity is involved in ATBF regulation through an endothelial-dependent mechanism in arteries. HFD treatment of mice causes a reduced eNOS expression in WAT and transgene eNOS overexpression in whole body endothelial cells protected against high-fat dietinduced obesity (50). In agreement, eNOS deficient mice exhibit systemic insulin resistance $(51,52)$. Although the genetic interventions are not specific to WAT endothelium but affects all endothelial cells, the data suggest an essential role of eNOS regulation and endothelial health.

We have recently shown that mice fed an HFD developed endothelial dysfunction, which was abrogated in mice with global knockout of the T-type $\mathrm{Ca}^{2+}$ channel Cav3.1 (53). Consistent with this, in hypertensive patients treated with $\mathrm{T}$ type/L-type channel blocker Efonidipine improved endothelial function (54), and pharmacological and genetic inhibition of Cav3.1 likewise protects against HFD-induced obesity in mice $(53,55)$. Cav3.1 is, among others, expressed in AT and endothelial cells (53), but the pharmacological and genetic inhibition studies of Cav3.1 do not pinpoint which cell types are involved in the phenotype. In endothelial cells, Cav3.1 interacts with eNOS (56). Nonetheless, global Cav3.1 knockout mice fed a regular diet display eNOS activity both in vivo and in vitro (56), and how Cav3.1 deficiency affects eNOS activity in HFD mice is still not known.

eNOS activity is also affected by caveolin-1 (Cav-1) - an integral membrane protein critically involved in the invagination of caveolae from the plasma membrane. Global Cav-1 knockout mice have endothelial dysfunction (57), and transgenic Cav-1 re-expression in the endothelium of Cav-1 knockout mice rescues the endothelial function (58). Cav-1 inhibits eNOS (59) and HFD-induced obesity increases vascular Cav-1 expression and accompanies impaired NO-mediated vasodilatation (60). In summary, the data suggest 
that adequate eNOS regulation in AT endothelial cells is important for ATBF and whole-body energy homeostasis, and that Cav-1 appears to play a significant role.

Cav-1 is not only expressed in vascular endothelial cells but also highly expressed in adipocytes. Recently knockout of the Cav1 gene in mice uncovered a significant extracellular vesicle (EV)-mediated signaling between endothelial cells and adipocytes (61).

\section{EXTRACELLULAR VESICLES ARE INVOLVED IN ENDOTHELIAL- ADIPOCYTES CROSSTALK}

The term EV encompasses several distinct vesicle types but can broadly be divided into microvesicles and exosomes (62). Microvesicles originate from the plasma membrane through outward budding, while exosomes are created through invagination of the plasma membrane that ultimately causes the formation of multivesicular bodies (MVB), which through fusion with the plasma membrane release exosomes to the extracellular medium. The EVs all contain constituents of a cell, including nucleic acid, lipids, and nuclear, cytosolic, and membrane proteins $(63,64)$. Although the function(s) of EVs are still unknown, the fact that all cells, pro- and eukaryotes (65), release EVs points to their contribution to normal physiology, and EV appears to be involved in cell-cell communication and cellular waste management.

\section{Extracellular Vesicles and Cell- Cell Communication}

EVs have been suggested as entities for horizontal transfer of genetic material and proteins between cells. RNA is the dominant form of nucleic acid in EVs, and EVs appear to be enriched for several specific RNA species, including a number of microRNAs (miRNAs). In agreement, it was detected early that the correlation between cellular and EV RNA concentrations was poor (66), hinting at an active transport of RNA molecule into vesicles. Indeed, a short RNA motif has been identified that guides RNA into EVs (67). Nonetheless, using the golden standard for EV isolation - differential ultracentrifugation has revealed that the average number of miRNAs per EV is low - approximate 1 miRNA per $100 \mathrm{EV}$ (68). This low RNA/EV ratio suggests that EVs and their cargo may be heterogeneous and that some EVs carry a lot of RNA while others are nonRNA-carriers. Consistent with this, new EV separation and isolation techniques such as asymmetric-flow field-flow fractionation indicate that there exists a much wider variety of EVs than has previously been recognized (69). It should be noted that the analysis of EVs is complicated, and current EVs isolation techniques carry a significant risk of analysis of contaminations such as co-precipitated RNAs and proteins (62). This is even true for EVs isolated from serum-free medium where supplements may carry a significant amount of miRNA (70). Interestingly, though, in humans and mice, adipocyte-derived EV contain a significant fraction of circulating miRNAs (71). This was determined using mice with adipocyte-specific knockout of Dicer, a critical enzyme required for the conversion of premiRNA molecules into a mature miRNA (71). Disruption of the adipocyte processing of miRNAs caused significantly reduced plasma EVs level of miRNAs (71). The circulating adipocyte EV reduced hepatic FGF21 expression causing a decreased plasma FGF21 level and improved glucose tolerance, indicating that the EV miRNAs were functional (71). Collectively, it appears that adipocyte-derived EVs mediated cell-to-cell communication that affects distant organ function and surrounding cells.

Hypoxia is a potent stimulator of EV secretion. EVs released from adipocytes cultured at $1 \% \mathrm{O}_{2}$, compared to normal air with $5 \% \mathrm{CO}_{2}$, and $\mathrm{EVs}$ from obese subjects impaired insulin-stimulated glucose uptake in adipocytes (72). Moreover, in the initial stages of HFD-induced AT expansion, the increased AT oxygen consumption limits $\mathrm{O}_{2}$ availability imposing a state of relative AT hypoxia that stimulated VEGF expression, and increased angiogenesis and HIF1 $\alpha$ expression (73). In 3T3-L1 adipocytes, proteomic analysis of the EVs from the normoxic $\left(20 \% \mathrm{O}_{2}\right)$ and low oxygen $\left(1 \% \mathrm{O}_{2}\right)$ cultured 3T3-L1 cells showed that 75 and 67 proteins were up- and down-regulated, respectively, by the low oxygen conditions and that the EVs were enriched in proteins involved in de novo lipogenesis (74). Importantly, the low oxygenderived EVs promoted the accumulation of lipids in recipient cells (74). EVs from liver cells are also important for lipid accumulation. Mice fed an HFD display rapid lipid accumulation in the liver (within hours), and the liver has been shown to respond to this by increased EV secretion (likely exosomes), which target adipocytes (75). Inhibition of EV secretion from liver cells by knockdown of Geranylgeranyl diphosphate synthase (Ggpps) improved glucose tolerance in HFD-fed mice but did not improve insulin resistance. The liverderived EVs enhance adipocyte lipid deposition by increasing lipogenesis and inhibiting lipid oxidation through Pgcl $\alpha$. Thus, liver cells may be an early metabolic sensor of lipid overload and respond by increased EV signaling to adipocytes (75).

In the WAT, the adipocytes are also targeted by EV derived from endothelial cells (61). Endothelial-derived EVs transferred Cav-1 protein to adipocytes, and, importantly, the EV-mediated transfer was regulated by fasting and feeding (61). Fasting increased endothelial Cav1 transfer, and this effect was blunted in HFD treated and $o b / o b$ mice (61). Although the glucagon receptor expression did not differ between WAT- and lungderived endothelial cells (61), glucagon only increased endothelial-derived EV secretion from WAT-derived endothelial cells (61). An essential function of the endothelial cells is the transcytosis of plasma components to the underlying parenchyma (29). Crewe et al. found that cultured endothelial cell-derived EVs were enriched in FBS-derived protein components (61). Glucagon and insulin increased BSA (fatty acid-free, low endotoxin) uptake in cultured endothelial cells, and Cav-1 participated in the process but was not essential for the glucagon and insulin-stimulated BSA uptake in endothelial cells (61). The BSA was secreted in EVs and indicates that endothelial cells contribute significantly to transcytosis by uptake of plasma components and secretion in EVs (61). Thus, 
the intercellular and interorgan EV communication to and from the WAT appears to be important for metabolic regulation.

\section{Extracellular Vesicles as Cellular Waste Management}

Accumulating evidence suggests that EVs are part of the cellular waste management system and shares many features with secretory autophagy (76). For example, blockage of EV secretion causes accumulation of harmful DNAs and activation of cellular damage response (77). The important role of autophagy for adipocytes and endothelial cells has been demonstrated in experimental models. Mice with the adipocyte-specific knockout of autophagy genes Atg3 and Atg16L had normal weight and body composition; however, the gene disruptions caused a massive influx of inflammatory cells in AT even in the regular diet-fed mice (78). This occurred without an increase in cytokines such as TNF- $\alpha$, IL-6, or MCP1 (78). The knockouts developed insulin resistance and impaired glucose tolerance, and together, suggests an essential role for adipocyte autophagy in the development of insulin resistance independent of obesity (78). Autophagy is also crucial for endothelial cells. Obesity-induced endothelial dysfunction is associated with the upregulation of endothelial autophagy machinery (79) and vascular ceramide content (80). Exosome production and release are modified by ceramide synthesis (81), and, interestingly, adiponectin signaling in endothelial cells increased exosome secretion and reduced cellular ceramide levels (74). Thus, exosome secretion may be a critical mechanism to reduce the intracellular accumulation of toxic material and endothelial dysfunction through adipocyte secretion of adiponectin.

\section{ADIPONECTIN - T-CADHERIN-AXIS AND CELLULAR CROSSTALK}

Adiponectin is an adipokine, which acts in an autocrine/ paracrine and endocrine fashion (82) and is highly expressed in human and mouse AT $(82,83)$. Various adipokines may play a key role in AT biology, on systemic metabolism or tissue crosstalk such as leptin, however, in this review we are only focusing on adiponectin. Typically, plasma concentration of adiponectin is high and in the micromolar range. Low adiponectin levels are reported in humans with metabolic diseases such as obesity and T2D (84) and are inversely correlated with insulin resistance (85) and fat mass in humans (86). Moreover, decreased levels of adiponectin are also reported in coronary artery disease (87) and myocardial infarction (88). Thus, reduced circulating adiponectin levels can reflect metabolic perturbations and can potentially serve as a critical marker of WAT fitness.

Adiponectin belongs to the C1q-like superfamily of protein, and its structure consists of a 22 collagen repeats and a Cterminal C1q-like globular domain (82). Endogenous adiponectin forms homo-oligomeric structures consisting of trimers, dimers of trimers, and 4- and 5-mers of trimers that is referred to as low molecular weight (LMW), medium molecular weight (MMW), and high molecular weight (HMW), respectively, complexes $(89,90)$ with different biological functions through binding of surface receptors (91-93).

Activation of the adiponectin receptors AdipoRs (94-96) and calreticulin (91) have important metabolic and immunological roles. Skeletal muscle is an important site of insulin-mediated glucose uptake; thus, considerable emphasis was placed on studying the possible metabolic effects of adiponectin on muscle. In cultured muscle cell lines, adiponectin improves insulin sensitivity (97), increases glucose uptake $(63,98)$ and increases fatty acid oxidation $(63,64)$. In mouse models of obesity and T2D, physiological doses of adiponectin enhanced insulin sensitivity (99). In muscle, adiponectin acts through AdipoR1 to activate AMPK (100). The anti-inflammatory effects of adiponectin have been demonstrated in different cell studies. Treatment of human macrophages with adiponectin revealed that adiponectin inhibits mature macrophages' phagocytic activity, and adiponectin also inhibited the lipopolysaccharide (LPS)-induced TNF- $\alpha$ production and TNF$\alpha$ mRNA expression (101). In line with this, another study showed that treatment of peritoneal macrophages with recombinant adiponectin enhanced transcript levels of a marker of the M2 phenotype such as IL-10 (102), indicating that adiponectin promotes macrophage polarization toward an anti-inflammatory M2 phenotype. In the liver, adiponectin binds to AdipoR1 and AdipoR2 to suppress hepatic glucose production and glycogenolysis (103), leading to reduced plasma glucose levels. Decreased hepatic glucose production can possibly be explained by studies showing that adiponectin suppresses the key regulators involved in gluconeogenesis, including phosphoenolpyruvate carboxykinase and glucose-6-phosphatase $(104,105)$.

In addition to adiponectin's beneficial effects on muscle and liver, it is also protective through its effects on the vascular endothelium (106). In the vascular endothelium, adiponectin acts through AdipoR1 and AdipoR2 to increase NO production through AMPK, which activates eNOS, leading to vasodilation (106). In addition to AdipoR1 and AdipoR2, endothelial cells also bind adiponectin through $\mathrm{T}$-cadherin expression.

As described above, adiponectin increases endothelial exosome secretion, and this effect is mediated through the binding of adiponectin to T-cadherin (107). T-cadherin is a member of the cadherin family, but in contrast to the other family members, it lacks a C-terminal intracellular domain and is attached to the extracellular side of the plasma membrane through a glycosylphosphatidylinositol (GPI)-anchor (108). There is strong in vivo support for the adiponectin/T-cadherin interaction from human and murine studies. Thus, genome wide-association studies (GWAS) for plasma adiponectin levels suggest the CDH13 (the gene encoding T-cadherin and outside of the $A D I P O Q$ locus) is strongly linked to adiponectin levels (109), and CDH13 single nucleotide polymorphisms (SNPs) are linked to increased adiponectin plasma levels in humans (110, 111). In mice, $T$-cadherin deficiency causes 3 -fold increased plasma adiponectin levels (112). T-cadherin is expressed in the heart, skeletal muscle, aorta, and vascular endothelium (112114). Adiponectin in its hexameric and HMW - but not trimeric 
and globular-forms bind T-cadherin $(92,115)$, and the Tcadherin expression tissues are also the site for the accumulation of HMW and hexameric adiponectin in mice (112-114, 116, 117), suggesting critical biological functions of the adiponectin binding to T-cadherin. Adiponectin and Tcadherin knockout mice have lower plasma exosome levels, and viral overexpression of adiponectin caused increased plasma exosome levels (107). The mechanisms and cellular signaling pathways that are involved are still unknown. It has, however, been shown that oligomerization of membraneanchored stimulates their sorting of cargo into exosome (118, 119); thus, the binding of the cellular attached T-cadherin to adiponectin might cause $\mathrm{T}$-cadherin oligomerization, internalization, and sorting into the multivesicular bodies (MVBs) before being released as exosomes. Thus, the crosstalk between adipocytes and endothelial cells involves EVs; however, this crosstalk's biological significance is still largely unknown but could be an important mechanism mediating tissue-crosstalk and endothelial health. Further research should be undertaken to investigate if other adipokines also play a key role in crosstalk mediated by EVs.

\section{CONCLUDING REMARKS AND FUTURE PERSPECTIVES}

The WAT microenvironment is critical for a whole-body metabolism; thus, gaining a mechanistic understanding of the crosstalk between the different cell populations in WAT is crucial. The endothelial cells are important for regulating WAT blood flow, and inadequate blood flow may cause hypoxia in the WAT and reduced adiponectin secretion (Figure 1). The reduced adiponectin secretion may cause reduced EV secretion from endothelial cells and thereby accelerate the development of endothelial dysfunction and decreasing adipocyte function further (Figure 1). The reduced adipocyte function affects multiple organs, e.g., through decreased adiponectin signaling in skeletal muscle, liver and the heart, and targeted treatment that restores the adipocyte/ endothelial crosstalk in WAT may thus provide therapeutic opportunities that improve whole-body metabolism.

Since the crosstalk involves physiological adaptations, such as changes in blood flow, and molecular changes, the investigations are heavily dependent on integrated models. In line with this, the exact role of EVs for WAT biology regulation also requires integrated models and needs the development of new experimental tools. The effect of EVs is often inferred from correlation studies, and tools that block exosome signaling in a cell-specific manner are still not available. The use of fluorescenttagged proteins that are transferred from endothelial cells to adipocytes has convincingly shown that transport does indeed occur between different cell types in vivo (61); however, to obtain information on EV function directly, cell-specific manipulation of EVs needs to be established. Possible solutions could be to use single-cell assays such as CD63-pHluorin $(120,121)$ and in vivo models for tracking intercellular EV communication (122). The

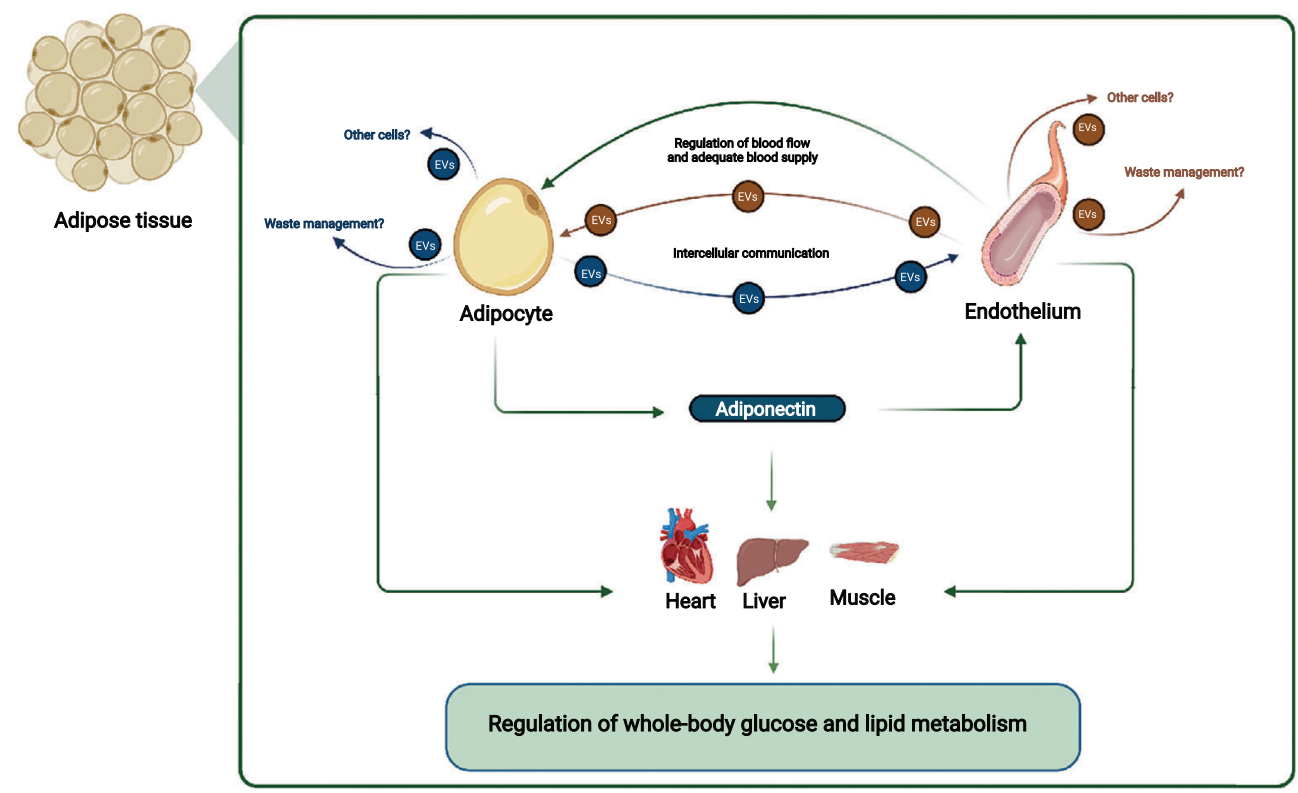

FIGURE 1 Adipocyte and endothelial crosstalk in adipose tissue contribute to regulation of whole-body glucose and lipid metabolism: In this working hypothesis, endothelial cells regulate blood flow adequately to adipocytes, which secrete adiponectin that communicate locally with endothelial cells and with distant organs such as muscle, liver, and heart. Adiponectin stimulates EV secretion from endothelial cells, ensuring their health e.g. through cellular waste management, and stimulates muscle, liver, and heart metabolism, improving systemic metabolism. EVs from adipocytes and endothelial cells may also target other cell types. Other adipocyte-derived factors, and overall endothelial health also contributes to regulation of whole-body glucose and lipid metabolism. Figure created with BioRender.com. 
tagged EVs will allow for cell-specific quantification of EV release rate and enable the identification of genetic and pharmacological interventions that interferes with EVs.

From a translational perspective, cells - including adipocytes and endothelial cells - release EVs to the circulation and provide non-invasive access to organs within the body. We have shown, using paired samples of human kidney and urine samples, that the EVs protein abundance is not a reliable marker of its tissue abundance (123). Nonetheless, the AT-derived EVs may be used to monitor clinical intervention studies and for early detection and differentiating of individual subjects based on whether or not they have healthy or unhealthy obesity. The identification of adipocyte- and endothelial-specific EV markers will provide an approach that enables the non-invasive interrogation of crosstalk between the cell-types in humans, enabling the translation of the findings from animal models to humans, and thereby provide

\section{REFERENCES}

1. Poirier P, Giles TD, Bray GA, Hong Y, Stern JS, Pi-Sunyer FX, et al. Obesity and Cardiovascular Disease: Pathophysiology, Evaluation, and Effect of Weight Loss. Arterioscler Thromb Vasc Biol (2006) 26(5):968-76. doi: 10.1161/01.ATV.0000216787.85457.f3

2. Frayn KN. Adipose Tissue as a Buffer for Daily Lipid Flux. Diabetologia (2002) 45(9):1201-10. doi: 10.1007/s00125-002-0873-y

3. Straub LG, Scherer PE. Metabolic Messengers: Adiponectin. Nat Metab (2019) 1(3):334-9. doi: 10.1038/s42255-019-0041-z

4. Sun K, Tordjman J, Clement K, Scherer PE. Fibrosis and Adipose Tissue Dysfunction. Cell Metab (2013) 18(4):470-7. doi: 10.1016/ j.cmet.2013.06.016

5. Jernas M, Palming J, Sjoholm K, Jennische E, Svensson PA, Gabrielsson BG, et al. Separation of Human Adipocytes by Size: Hypertrophic Fat Cells Display Distinct Gene Expression. FASEB J (2006) 20(9):1540-2. doi: 10.1096/fj.05-5678fje

6. Bora P, Majumdar AS. Adipose Tissue-Derived Stromal Vascular Fraction in Regenerative Medicine: A Brief Review on Biology and Translation. Stem Cell Res Ther (2017) 8(1):145. doi: 10.1186/s13287-017-0598-y

7. Ye J, Gao Z, Yin J, He Q. Hypoxia is a Potential Risk Factor for Chronic Inflammation and Adiponectin Reduction in Adipose Tissue of $\mathrm{Ob} / \mathrm{Ob}$ and Dietary Obese Mice. Am J Physiol Endocrinol Metab (2007) 293(4):E111828. doi: 10.1152/ajpendo.00435.2007

8. Halberg N, Khan T, Trujillo ME, Wernstedt-Asterholm I, Attie AD, Sherwani S, et al. Hypoxia-Inducible Factor 1alpha Induces Fibrosis and Insulin Resistance in White Adipose Tissue. Mol Cell Biol (2009) 29 (16):4467-83. doi: 10.1128/MCB.00192-09

9. Wang B, Wood IS, Trayhurn P. Dysregulation of the Expression and Secretion of Inflammation-Related Adipokines by Hypoxia in Human Adipocytes. Pflugers Arch (2007) 455(3):479-92. doi: 10.1007/s00424-0070301-8

10. Lee KY, Gesta S, Boucher J, Wang XL, Kahn CR. The Differential Role of Hiflbeta/Arnt and the Hypoxic Response in Adipose Function, Fibrosis, and Inflammation. Cell Metab (2011) 14(4):491-503. doi: 10.1016/ j.cmet.2011.08.006

11. Frayn KN, Karpe F. Regulation of Human Subcutaneous Adipose Tissue Blood Flow. Int J Obes (Lond) (2014) 38(8):1019-26. doi: 10.1038/ ijo.2013.200

12. Goossens GH, Bizzarri A, Venteclef N, Essers Y, Cleutjens JP, Konings E, et al. Increased Adipose Tissue Oxygen Tension in Obese Compared With Lean Men is Accompanied by Insulin Resistance, Impaired Adipose Tissue Capillarization, and Inflammation. Circulation (2011) 124(1):67-76. doi: 10.1161/ CIRCULATIONAHA.111.027813

13. Pasarica M, Sereda OR, Redman LM, Albarado DC, Hymel DT, Roan LE, et al. Reduced Adipose Tissue Oxygenation in Human Obesity: Evidence for new treatment options for alleviation of the negative health impacts of obesity.

\section{AUTHOR CONTRIBUTIONS}

RS prepared the figure. RS and PS drafted the manuscript. RS, PS revised the manuscript. Both authors contributed to the article and approved the submitted version.

\section{FUNDING}

Steno Diabetes Center Odense funded by the Novo Nordic Foundation (RS), and the Novo Nordisk Foundation (grant no NNF20OC0063791 to PS).

Rarefaction, Macrophage Chemotaxis, and Inflammation Without an Angiogenic Response. Diabetes (2009) 58(3):718-25. doi: 10.2337/db081098

14. Cifarelli V, Beeman SC, Smith GI, Yoshino J, Morozov D, Beals JW, et al. Decreased Adipose Tissue Oxygenation Associates With Insulin Resistance in Individuals With Obesity. J Clin Invest (2020) 130(12):6688-99. doi: 10.1172/JCI141828

15. Todorcevic M, Manuel AR, Austen L, Michailidou Z, Hazlehurst JM, Neville M, et al. Markers of Adipose Tissue Hypoxia are Elevated in Subcutaneous Adipose Tissue of Severely Obese Patients With Obesity Hypoventilation Syndrome But Not in the Moderately Obese. Int J Obes (Lond) (2021) 45 (7):1618-22. doi: 10.1038/s41366-021-00793-7

16. An YA, Sun K, Joffin N, Zhang F, Deng Y, Donze O, et al. Angiopoietin-2 in White Adipose Tissue Improves Metabolic Homeostasis Through Enhanced Angiogenesis. Elife (2017) 6:e24071. doi: 10.7554/ eLife. 24071

17. Sung HK, Doh KO, Son JE, Park JG, Bae Y, Choi S, et al. Adipose Vascular Endothelial Growth Factor Regulates Metabolic Homeostasis Through Angiogenesis. Cell Metab (2013) 17(1):61-72. doi: 10.1016/ j.cmet.2012.12.010

18. Seki T, Hosaka K, Fischer C, Lim S, Andersson P, Abe M, et al. Ablation of Endothelial VEGFR1 Improves Metabolic Dysfunction by Inducing Adipose Tissue Browning. J Exp Med (2018) 215(2):611-26. doi: 10.1084/ jem.20171012

19. Robciuc MR, Kivela R, Williams IM, de Boer JF, van Dijk TH, Elamaa H, et al. VEGFB/VEGFR1-Induced Expansion of Adipose Vasculature Counteracts Obesity and Related Metabolic Complications. Cell Metab (2016) 23(4):712-24. doi: 10.1016/j.cmet.2016.03.004

20. Elias I, Franckhauser S, Ferre T, Vila L, Tafuro S, Munoz S, et al. Adipose Tissue Overexpression of Vascular Endothelial Growth Factor Protects Against DietInduced Obesity and Insulin Resistance. Diabetes (2012) 61(7):1801-13. doi: $10.2337 / \mathrm{db} 11-0832$

21. Sun K, Wernstedt Asterholm I, Kusminski CM, Bueno AC, Wang ZV, Pollard JW, et al. Dichotomous Effects of VEGF-A on Adipose Tissue Dysfunction. Proc Natl Acad Sci USA (2012) 109(15):5874-9. doi: 10.1073/ pnas. 1200447109

22. Weinstock A, Brown EJ, Garabedian ML, Pena S, Sharma M, Lafaille J, et al. Single-Cell RNA Sequencing of Visceral Adipose Tissue Leukocytes Reveals That Caloric Restriction Following Obesity Promotes the Accumulation of a Distinct Macrophage Population With Features of Phagocytic Cells. Immunometabolism (2019) 1:e190008. doi: 10.20900/immunometab 20190008

23. Rajbhandari P, Arneson D, Hart SK, Ahn IS, Diamante G, Santos LC, et al. Single Cell Analysis Reveals Immune Cell-Adipocyte Crosstalk Regulating the Transcription of Thermogenic Adipocytes. Elife (2019) 8:e49501. doi: 10.7554/eLife.49501 
24. Vijay J, Gauthier MF, Biswell RL, Louiselle DA, Johnston JJ, Cheung WA, et al. Single-Cell Analysis of Human Adipose Tissue Identifies Depot and Disease Specific Cell Types. Nat Metab (2020) 2(1):97-109. doi: 10.1038/ s42255-019-0152-6

25. Escobedo N, Oliver G. The Lymphatic Vasculature: Its Role in Adipose Metabolism and Obesity. Cell Metab (2017) 26(4):598-609. doi: 10.1016/ j.cmet.2017.07.020

26. Sun K, Kusminski CM, Scherer PE. Adipose Tissue Remodeling and Obesity. J Clin Invest (2011) 121(6):2094-101. doi: 10.1172/JCI45887

27. Harvey NL, Srinivasan RS, Dillard ME, Johnson NC, Witte MH, Boyd K, et al. Lymphatic Vascular Defects Promoted by Prox1 Haploinsufficiency Cause Adult-Onset Obesity. Nat Genet (2005) 37(10):1072-81. doi: 10.1038/ ng1642

28. Patsouris D, Li PP, Thapar D, Chapman J, Olefsky JM, Neels JG. Ablation of CD11c-Positive Cells Normalizes Insulin Sensitivity in Obese Insulin Resistant Animals. Cell Metab (2008) 8(4):301-9. doi: 10.1016/ j.cmet.2008.08.015

29. Potente M, Makinen T. Vascular Heterogeneity and Specialization in Development and Disease. Nat Rev Mol Cell Biol (2017) 18(8):477-94. doi: $10.1038 / \mathrm{nrm} .2017 .36$

30. De Bock K, Georgiadou M, Schoors S, Kuchnio A, Wong BW, Cantelmo AR, et al. Role of PFKFB3-Driven Glycolysis in Vessel Sprouting. Cell (2013) 154 (3):651-63. doi: 10.1016/j.cell.2013.06.037

31. Kaiser N, Sasson S, Feener EP, Boukobza-Vardi N, Higashi S, Moller DE, et al. Differential Regulation of Glucose Transport and Transporters by Glucose in Vascular Endothelial and Smooth Muscle Cells. Diabetes (1993) 42(1):80-9. doi: 10.2337/diabetes.42.1.80

32. Eelen G, de Zeeuw P, Treps L, Harjes U, Wong BW, Carmeliet P. Endothelial Cell Metabolism. Physiol Rev (2018) 98(1):3-58. doi: 10.1152/ physrev.00001.2017

33. Kubota T, Kubota N, Kumagai H, Yamaguchi S, Kozono H, Takahashi T, et al. Impaired Insulin Signaling in Endothelial Cells Reduces InsulinInduced Glucose Uptake by Skeletal Muscle. Cell Metab (2011) 13(3):294307. doi: 10.1016/j.cmet.2011.01.018

34. Mather KJ, Verma S, Anderson TJ. Improved Endothelial Function With Metformin in Type 2 Diabetes Mellitus. J Am Coll Cardiol (2001) 37 (5):1344-50. doi: 10.1016/S0735-1097(01)01129-9

35. Feletou M, Kohler R, Vanhoutte PM. Nitric Oxide: Orchestrator of Endothelium-Dependent Responses. Ann Med (2012) 44(7):694-716. doi: 10.3109/07853890.2011.585658

36. Heitzer T, Schlinzig T, Krohn K, Meinertz T, Munzel T. Endothelial Dysfunction, Oxidative Stress, and Risk of Cardiovascular Events in Patients With Coronary Artery Disease. Circulation (2001) 104(22):2673-8. doi: $10.1161 /$ hc4601.099485

37. Zhou E, Qing D, Li J. Age-Associated Endothelial Dysfunction in Rat Mesenteric Arteries: Roles of Calcium-Activated $\mathrm{K}(+)$ Channels (K(ca)). Physiol Res (2010) 59(4):499-508. doi: 10.33549/physiolres.931761

38. Luscher TF, Vanhoutte PM. Endothelium-Dependent Contractions to Acetylcholine in the Aorta of the Spontaneously Hypertensive Rat. Hypertension (1986) 8(4):344-8. doi: 10.1161/01.HYP.8.4.344

39. Van Guilder GP, Hoetzer GL, Dengel DR, Stauffer BL, DeSouza CA. Impaired Endothelium-Dependent Vasodilation in Normotensive and Normoglycemic Obese Adult Humans. J Cardiovasc Pharmacol (2006) 47 (2):310-3. doi: 10.1097/01.fjc.0000205097.29946.d3

40. Du J, Fan LM, Mai A, Li JM. Crucial Roles of Nox2-Derived Oxidative Stress in Deteriorating the Function of Insulin Receptors and Endothelium in Dietary Obesity of Middle-Aged Mice. Br J Pharmacol (2013) 170(5):106477. doi: $10.1111 /$ bph. 12336

41. Steinberg HO, Chaker H, Leaming R, Johnson A, Brechtel G, Baron AD. Obesity/insulin Resistance Is Associated With Endothelial Dysfunction. Implications for the Syndrome of Insulin Resistance. J Clin Invest (1996) 97(11):2601-10. doi: 10.1172/JCI118709

42. Liu JT, Song E, Xu A, Berger T, Mak TW, Tse HF, et al. Lipocalin-2 Deficiency Prevents Endothelial Dysfunction Associated With Dietary Obesity: Role of Cytochrome P450 2C Inhibition. Br J Pharmacol (2012) 165(2):520-31. doi: 10.1111/j.1476-5381.2011.01587.x

43. Ketonen J, Pilvi T, Mervaala E. Caloric Restriction Reverses High-Fat DietInduced Endothelial Dysfunction and Vascular Superoxide Production in
C57Bl/6 Mice. Heart Vessels (2010) 25(3):254-62. doi: 10.1007/s00380-009$1182-\mathrm{x}$

44. Karpe F, Fielding BA, Ilic V, Macdonald IA, Summers LK, Frayn KN. Impaired Postprandial Adipose Tissue Blood Flow Response is Related to Aspects of Insulin Sensitivity. Diabetes (2002) 51(8):2467-73. doi: 10.2337/ diabetes.51.8.2467

45. Karpe F, Fielding BA, Ardilouze JL, Ilic V, Macdonald IA, Frayn KN. Effects of Insulin on Adipose Tissue Blood Flow in Man. J Physiol (2002) 540(Pt 3):1087-93. doi: 10.1113/jphysiol.2001.013358

46. Patel JN, Eisenhofer G, Coppack SW, Miles JM. Norepinephrine Spillover in Forearm and Subcutaneous Adipose Tissue Before and After Eating. J Clin Endocrinol Metab (1999) 84(8):2815-9. doi: 10.1210/jc.84.8.2815

47. Cocks TM, Angus JA. Endothelium-Dependent Relaxation of Coronary Arteries by Noradrenaline and Serotonin. Nature (1983) 305(5935):627-30. doi: $10.1038 / 305627 \mathrm{a} 0$

48. Goossens GH, McQuaid SE, Dennis AL, van Baak MA, Blaak EE, Frayn KN, et al. Angiotensin II: A Major Regulator of Subcutaneous Adipose Tissue Blood Flow in Humans. J Physiol (2006) 571(Pt 2):451-60. doi: 10.1113/ jphysiol.2005.101352

49. Ardilouze JL, Fielding BA, Currie JM, Frayn KN, Karpe F. Nitric Oxide and Beta-Adrenergic Stimulation are Major Regulators of Preprandial and Postprandial Subcutaneous Adipose Tissue Blood Flow in Humans. Circulation (2004) 109(1):47-52. doi: 10.1161/01.CIR.0000105681. 70455.73

50. Sansbury BE, Cummins TD, Tang Y, Hellmann J, Holden CR, Harbeson MA, et al. Overexpression of Endothelial Nitric Oxide Synthase Prevents Diet-Induced Obesity and Regulates Adipocyte Phenotype. Circ Res (2012) 111(9):1176-89. doi: 10.1161/CIRCRESAHA.112.266395

51. Shankar RR, Wu Y, Shen HQ, Zhu JS, Baron AD. Mice With Gene Disruption of Both Endothelial and Neuronal Nitric Oxide Synthase Exhibit Insulin Resistance. Diabetes (2000) 49(5):684-7. doi: 10.2337/ diabetes.49.5.684

52. Duplain H, Burcelin R, Sartori C, Cook S, Egli M, Lepori M, et al. Insulin Resistance, Hyperlipidemia, and Hypertension in Mice Lacking Endothelial Nitric Oxide Synthase. Circulation (2001) 104(3):342-5. doi: 10.1161/ 01.CIR.104.3.342

53. Rosenstand K, Andersen K, Terp R, Gennemark P, Ellman DG, Reznichenko A, et al. Deficiency of T-Type Voltage-Gated Calcium Channels Results in Attenuated Weight Gain and Improved Endothelium-Dependent Dilatation of Resistance Vessels Induced by a High-Fat Diet in Mice. J Physiol Biochem (2020) 76(1):135-45. doi: 10.1007/s13105-020-00728-2

54. Koh KK, Quon MJ, Lee SJ, Han SH, Ahn JY, Kim JA, et al. Efonidipine Simultaneously Improves Blood Pressure, Endothelial Function, and Metabolic Parameters in Nondiabetic Patients With Hypertension. Diabetes Care (2007) 30(6):1605-7. doi: 10.2337/dc06-2267

55. Uebele VN, Gotter AL, Nuss CE, Kraus RL, Doran SM, Garson SL, et al. Antagonism of T-Type Calcium Channels Inhibits High-Fat Diet-Induced Weight Gain in Mice. J Clin Invest (2009) 119(6):1659-67. doi: 10.1172/ JCI36954

56. Svenningsen $\mathrm{P}$, Andersen K, Thuesen AD, Shin HS, Vanhoutte PM, Skott O, et al. T-Type $\mathrm{Ca}(2+)$ Channels Facilitate NO-Formation, Vasodilatation and NO-Mediated Modulation of Blood Pressure. Pflugers Arch (2014) 466 (12):2205-14. doi: 10.1007/s00424-014-1492-4

57. Drab M, Verkade P, Elger M, Kasper M, Lohn M, Lauterbach B, et al. Loss of Caveolae, Vascular Dysfunction, and Pulmonary Defects in Caveolin-1 Gene-Disrupted Mice. Science (2001) 293(5539):2449-52. doi: 10.1126/ science. 1062688

58. Murata T, Lin MI, Huang Y, Yu J, Bauer PM, Giordano FJ, et al Reexpression of Caveolin-1 in Endothelium Rescues the Vascular, Cardiac, and Pulmonary Defects in Global Caveolin-1 Knockout Mice. J Exp Med (2007) 204(10):2373-82. doi: 10.1084/jem.20062340

59. Schubert W, Frank PG, Woodman SE, Hyogo H, Cohen DE, Chow CW, et al. Microvascular Hyperpermeability in Caveolin-1 (-/-) Knock-Out Mice. Treatment With a Specific Nitric-Oxide Synthase Inhibitor, L-NAME, Restores Normal Microvascular Permeability in Cav-1 Null Mice. J Biol Chem (2002) 277(42):40091-8. doi: 10.1074/jbc.M205948200

60. Grayson TH, Chadha PS, Bertrand PP, Chen H, Morris MJ, Senadheera S, et al. Increased Caveolae Density and Caveolin-1 Expression Accompany 
Impaired NO-Mediated Vasorelaxation in Diet-Induced Obesity. Histochem Cell Biol (2013) 139(2):309-21. doi: 10.1007/s00418-012-1032-2

61. Crewe C, Joffin N, Rutkowski JM, Kim M, Zhang F, Towler DA, et al. An Endothelial-To-Adipocyte Extracellular Vesicle Axis Governed by Metabolic State. Cell (2018) 175(3):695-708.e613. doi: 10.1016/j.cell.2018.09.005

62. Svenningsen P, Sabaratnam R, Jensen BL. Urinary Extracellular Vesicles: Origin, Role as Intercellular Messengers and Biomarkers; Efficient Sorting and Potential Treatment Options. Acta Physiol (Oxf) (2020) 228(1):e13346. doi: 10.1111/apha.13346

63. Yamauchi T, Kamon J, Minokoshi Y, Ito Y, Waki H, Uchida S, et al. Adiponectin Stimulates Glucose Utilization and Fatty-Acid Oxidation by Activating AMP-Activated Protein Kinase. Nat Med (2002) 8(11):1288-95. doi: $10.1038 / \mathrm{nm} 788$

64. Yoon MJ, Lee GY, Chung JJ, Ahn YH, Hong SH, Kim JB. Adiponectin Increases Fatty Acid Oxidation in Skeletal Muscle Cells by Sequential Activation of AMP-Activated Protein Kinase, P38 Mitogen-Activated Protein Kinase, and Peroxisome Proliferator-Activated Receptor Alpha. Diabetes (2006) 55(9):2562-70. doi: 10.2337/db05-1322

65. Kalluri R, LeBleu VS. The Biology, Function, and Biomedical Applications of Exosomes. Science (2020) 367(6478):eaau6977. doi: 10.1126/science.aau6977

66. Valadi H, Ekstrom K, Bossios A, Sjostrand M, Lee JJ, Lotvall JO. ExosomeMediated Transfer of mRNAs and microRNAs Is a Novel Mechanism of Genetic Exchange Between Cells. Nat Cell Biol (2007) 9(6):654-9. doi: 10.1038/ncb1596

67. Villarroya-Beltri C, Gutierrez-Vazquez C, Sanchez-Cabo F, PerezHernandez D, Vazquez J, Martin-Cofreces N, et al. Sumoylated Hnrnpa2b1 Controls the Sorting of miRNAs Into Exosomes Through Binding to Specific Motifs. Nat Commun (2013) 4:2980. doi: 10.1038/ ncomms 3980

68. Chevillet JR, Kang Q, Ruf IK, et al. Quantitative and Stoichiometric Analysis of the microRNA Content of Exosomes. Proc Natl Acad Sci USA (2014) 111 (41):14888-93. doi: 10.1073/pnas.1408301111

69. Zhang H, Freitas D, Kim HS, Fabijanic K, Li Z, Chen H, et al. Identification of Distinct Nanoparticles and Subsets of Extracellular Vesicles by Asymmetric Flow Field-Flow Fractionation. Nat Cell Biol (2018) 20 (3):332-43. doi: 10.1038/s41556-018-0040-4

70. Auber M, Frohlich D, Drechsel O, Karaulanov E, Kramer-Albers EM. Serum-Free Media Supplements Carry miRNAs That Co-Purify With Extracellular Vesicles. J Extracell Vesicles (2019) 8(1):1656042. doi: 10.1080/20013078.2019.1656042

71. Thomou T, Mori MA, Dreyfuss JM, Konishi M, Sakaguchi M, Wolfrum C, et al. Adipose-Derived Circulating miRNAs Regulate Gene Expression in Other Tissues. Nature (2017) 542(7642):450-5. doi: 10.1038/nature21365

72. Mleczko J, Ortega FJ, Falcon-Perez JM, Wabitsch M, Fernandez-Real JM, Mora S. Extracellular Vesicles From Hypoxic Adipocytes and Obese Subjects Reduce Insulin-Stimulated Glucose Uptake. Mol Nutr Food Res (2018) 62 (5):1700917. doi: 10.1002/mnfr.201700917

73. Graupera M, Claret M. Endothelial Cells: New Players in Obesity and Related Metabolic Disorders. Trends Endocrinol Metab (2018) 29(11):78194. doi: 10.1016/j.tem.2018.09.003

74. Sano S, Izumi Y, Yamaguchi T, Yamazaki T, Tanaka M, Shiota M, et al. Lipid Synthesis is Promoted by Hypoxic Adipocyte-Derived Exosomes in 3T3-L1 Cells. Biochem Biophys Res Commun (2014) 445(2):327-33. doi: 10.1016/ j.bbrc.2014.01.183

75. Zhao Y, Zhao MF, Jiang S, Wu J, Liu J, Yuan XW, et al. Liver Governs Adipose Remodelling via Extracellular Vesicles in Response to Lipid Overload. Nat Commun (2020) 11(1):719. doi: 10.1038/s41467-020-14450-6

76. Gudbergsson JM, Johnsen KB. Exosomes and Autophagy: Rekindling the Vesicular Waste Hypothesis. J Cell Commun Signal (2019) 13(4):443-50. doi: 10.1007/s12079-019-00524-8

77. Takahashi A, Okada R, Nagao K, Kawamata Y, Hanyu A, Yoshimoto S, et al. Exosomes Maintain Cellular Homeostasis by Excreting Harmful DNA From Cells. Nat Commun (2017) 8:15287. doi: 10.1038/ncomms15287

78. Cai J, Pires KM, Ferhat M, Chaurasia B, Buffolo MA, Smalling R, et al. Autophagy Ablation in Adipocytes Induces Insulin Resistance and Reveals Roles for Lipid Peroxide and Nrf2 Signaling in Adipose-Liver Crosstalk. Cell Rep (2018) 25(7):1708-17.e1705. doi: 10.1016/j.celrep. 2018.10.040
79. Dong Q, Xing W, Su F, Liang X, Tian F, Gao F, et al. Tetrahydroxystilbene Glycoside Improves Microvascular Endothelial Dysfunction and Ameliorates Obesity-Associated Hypertension in Obese ZDF Rats Via Inhibition of Endothelial Autophagy. Cell Physiol Biochem (2017) 43 (1):293-307. doi: 10.1159/000480410

80. Zhang QJ, Holland WL, Wilson L, Tanner JM, Kearns D, Cahoon JM, et al. Ceramide Mediates Vascular Dysfunction in Diet-Induced Obesity by PP2AMediated Dephosphorylation of the eNOS-Akt Complex. Diabetes (2012) 61 (7):1848-59. doi: 10.2337/db11-1399

81. Trajkovic K, Hsu C, Chiantia S, Rajendran L, Wenzel D, Wieland F, et al. Ceramide Triggers Budding of Exosome Vesicles Into Multivesicular Endosomes. Science (2008) 319(5867):1244-7. doi: 10.1126/science.1153124

82. Scherer PE, Williams S, Fogliano M, Baldini G, Lodish HF. A Novel Serum Protein Similar to C1q, Produced Exclusively in Adipocytes. J Biol Chem (1995) 270(45):26746-9. doi: 10.1074/jbc.270.45.26746

83. Maeda K, Okubo K, Shimomura I, Funahashi T, Matsuzawa Y, Matsubara K. cDNA Cloning and Expression of a Novel Adipose Specific CollagenLike Factor, Apm1 (AdiPose Most Abundant Gene Transcript 1). Biochem Biophys Res Commun (1996) 221(2):286-9. doi: 10.1006/ bbrc.1996.0587

84. Spranger J, Kroke A, Mohlig M, Bergmann MM, Ristow M, Boeing H, et al. Adiponectin and Protection Against Type 2 Diabetes Mellitus. Lancet (2003) 361(9353):226-8. doi: 10.1016/S0140-6736(03)12255-6

85. Cnop M, Havel PJ, Utzschneider KM, Carr DB, Sinha MK, Boyko EJ, et al. Relationship of Adiponectin to Body Fat Distribution, Insulin Sensitivity and Plasma Lipoproteins: Evidence for Independent Roles of Age and Sex. Diabetologia (2003) 46(4):459-69. doi: 10.1007/s00125-003-1074-z

86. Arita Y, Kihara S, Ouchi N, Takahashi M, Maeda K, Miyagawa J, et al. Paradoxical Decrease of an Adipose-Specific Protein, Adiponectin, in Obesity. Biochem Biophys Res Commun (1999) 257(1):79-83. doi: 10.1006/ bbrc. 1999.0255

87. Ouchi N, Kihara S, Arita Y, Maeda K, Kuriyama H, Okamoto Y, et al. Novel Modulator for Endothelial Adhesion Molecules: Adipocyte-Derived Plasma Protein Adiponectin. Circulation (1999) 100(25):2473-6. doi: 10.1161/ 01.CIR.100.25.2473

88. Pischon T, Girman CJ, Hotamisligil GS, Rifai N, Hu FB, Rimm EB. Plasma Adiponectin Levels and Risk of Myocardial Infarction in Men. JAMA (2004) 291(14):1730-7. doi: 10.1001/jama.291.14.1730

89. Tsao TS, Murrey HE, Hug C, Lee DH, Lodish HF. Oligomerization StateDependent Activation of NF-Kappa B Signaling Pathway by Adipocyte Complement-Related Protein of $30 \mathrm{kDa}$ (Acrp30). J Biol Chem (2002) 277 (33):29359-62. doi: 10.1074/jbc.C200312200

90. Tsao TS, Tomas E, Murrey HE, Hug C, Lee DH, Ruderman NB, et al. Role of Disulfide Bonds in Acrp30/adiponectin Structure and Signaling Specificity. Different Oligomers Activate Different Signal Transduction Pathways. J Biol Chem (2003) 278(50):50810-7. doi: 10.1074/jbc. M309469200

91. Takemura Y, Ouchi N, Shibata R, Aprahamian T, Kirber MT, Summer RS, et al. Adiponectin Modulates Inflammatory Reactions via Calreticulin Receptor-Dependent Clearance of Early Apoptotic Bodies. J Clin Invest (2007) 117(2):375-86. doi: 10.1172/JCI29709

92. Hug C, Wang J, Ahmad NS, Bogan JS, Tsao TS. Lodish HF. T-Cadherin is a Receptor for Hexameric and High-Molecular-Weight Forms of Acrp30/ adiponectin. Proc Natl Acad Sci USA (2004) 101(28):10308-13. doi: 10.1073/ pnas. 0403382101

93. Yamauchi T, Kamon J, Ito Y, Tsuchida A, Yokomizo T, Kita S, et al. Cloning of Adiponectin Receptors That Mediate Antidiabetic Metabolic Effects. Nature (2003) 423(6941):762-9. doi: 10.1038/nature01705

94. Iwabu M, Yamauchi T, Okada-Iwabu M, Sato K, Nakagawa T, Funata M, et al. Adiponectin and AdipoR1 Regulate PGC-1alpha and Mitochondria by $\mathrm{Ca}(2+)$ and AMPK/Sirt1. Nature (2010) 464(7293):1313-9. doi: 10.1038/ nature08991

95. Holland WL, Miller RA, Wang ZV, Sun K, Barth BM, Bui HH, et al. Receptor-Mediated Activation of Ceramidase Activity Initiates the Pleiotropic Actions of Adiponectin. Nat Med (2011) 17(1):55-63. doi: $10.1038 / \mathrm{nm} .2277$

96. Yamauchi T, Nio Y, Maki T, Kobayashi M, Takazawa T, Iwabu M, et al. Targeted Disruption of AdipoR1 and AdipoR2 Causes Abrogation of 
Adiponectin Binding and Metabolic Actions. Nat Med (2007) 13(3):332-9. doi: $10.1038 / \mathrm{nm} 1557$

97. Wang C, Mao X, Wang L, Liu M, Wetzel MD, Guan KL, et al. Adiponectin Sensitizes Insulin Signaling by Reducing P70 S6 Kinase-Mediated Serine Phosphorylation of IRS-1. J Biol Chem (2007) 282(11):7991-6. doi: 10.1074/ jbc.M700098200

98. Ceddia RB, Somwar R, Maida A, Fang X, Bikopoulos G, Sweeney G. Globular Adiponectin Increases GLUT4 Translocation and Glucose Uptake But Reduces Glycogen Synthesis in Rat Skeletal Muscle Cells. Diabetologia (2005) 48(1):132-9. doi: 10.1007/s00125-004-1609-y

99. Yamauchi T, Kamon J, Waki H, Terauchi Y, Kubota N, Hara K, et al. The Fat-Derived Hormone Adiponectin Reverses Insulin Resistance Associated With Both Lipoatrophy and Obesity. Nat Med (2001) 7(8):941-6. doi: $10.1038 / 90984$

100. Chen MB, McAinch AJ, Macaulay SL, Castelli LA, O'Brien PE, Dixon JB, et al. Impaired Activation of AMP-Kinase and Fatty Acid Oxidation by Globular Adiponectin in Cultured Human Skeletal Muscle of Obese Type 2 Diabetics. J Clin Endocrinol Metab (2005) 90(6):3665-72. doi: 10.1210/ jc.2004-1980

101. Yokota T, Oritani K, Takahashi I, Ishikawa J, Matsuyama A, Ouchi N, et al. Adiponectin, a New Member of the Family of Soluble Defense Collagens, Negatively Regulates the Growth of Myelomonocytic Progenitors and the Functions of Macrophages. Blood (2000) 96(5):1723-32. doi: 10.1182/ blood.V96.5.1723.h8001723_1723_1732

102. Ohashi K, Parker JL, Ouchi N, Higuchi A, Vita JA, Gokce N, et al. Adiponectin Promotes Macrophage Polarization Toward an AntiInflammatory Phenotype. J Biol Chem (2010) 285(9):6153-60. doi: 10.1074/jbc.M109.088708

103. Combs TP, Berg AH, Obici S, Scherer PE, Rossetti L. Endogenous Glucose Production Is Inhibited by the Adipose-Derived Protein Acrp30. J Clin Invest (2001) 108(12):1875-81. doi: 10.1172/JCI14120

104. Berg AH, Combs TP, Du X, Brownlee M, Scherer PE. The AdipocyteSecreted Protein Acrp30 Enhances Hepatic Insulin Action. Nat Med (2001) 7 (8):947-53. doi: 10.1038/90992

105. Miller RA, Chu Q, Le Lay J, Scherer PE, Ahima RS, Kaestner KH, et al. Adiponectin Suppresses Gluconeogenic Gene Expression in Mouse Hepatocytes Independent of LKB1-AMPK Signaling. J Clin Invest (2011) 121(6):2518-28. doi: 10.1172/JCI45942

106. Vaiopoulos AG, Marinou K, Christodoulides C, Koutsilieris M. The Role of Adiponectin in Human Vascular Physiology. Int J Cardiol (2012) 155 (2):188-93. doi: 10.1016/j.ijcard.2011.07.047

107. Obata Y, Kita S, Koyama Y, Fukuda S, Takeda H, Takahashi M, et al. Adiponectin/T-Cadherin System Enhances Exosome Biogenesis and Decreases Cellular Ceramides by Exosomal Release. JCI Insight (2018) 3 (8):e99680. doi: 10.1172/jci.insight.99680

108. Ranscht B. Dours-Zimmermann MT. T-Cadherin, a Novel Cadherin Cell Adhesion Molecule in the Nervous System Lacks the Conserved Cytoplasmic Region. Neuron (1991) 7(3):391-402. doi: 10.1016/08966273(91)90291-7

109. Chung CM, Lin TH, Chen JW, Leu HB, Yang HC, Ho HY, et al. A GenomeWide Association Study Reveals a Quantitative Trait Locus of Adiponectin on CDH13 That Predicts Cardiometabolic Outcomes. Diabetes (2011) 60 (9):2417-23. doi: 10.2337/db10-1321

110. Borges MC, Lawlor DA, de Oliveira C, White J, Horta BL, Barros AJ. Role of Adiponectin in Coronary Heart Disease Risk: A Mendelian Randomization Study. Circ Res (2016) 119(3):491-9. doi: 10.1161/CIRCRESAHA. 116.308716

111. Kitamoto A, Kitamoto T, Nakamura T, Matsuo T, Nakata Y, Hyogo H, et al. $\mathrm{CDH} 13$ Polymorphisms Are Associated With Adiponectin Levels and Metabolic Syndrome Traits Independently of Visceral Fat Mass. J Atheroscler Thromb (2016) 23(3):309-19. doi: 10.5551/jat.31567
112. Matsuda K, Fujishima Y, Maeda N, Mori T, Hirata A, Sekimoto R, et al. Positive Feedback Regulation Between Adiponectin and T-Cadherin Impacts Adiponectin Levels in Tissue and Plasma of Male Mice. Endocrinology (2015) 156(3):934-46. doi: 10.1210/en.2014-1618

113. Denzel MS, Scimia MC, Zumstein PM, Walsh K, Ruiz-Lozano P. Ranscht B. T-Cadherin is Critical for Adiponectin-Mediated Cardioprotection in Mice. J Clin Invest (2010) 120(12):4342-52. doi: 10.1172/JCI43464

114. Parker-Duffen JL, Nakamura K, Silver M, Kikuchi R, Tigges U, Yoshida S, et al. T-Cadherin is Essential for Adiponectin-Mediated Revascularization. J Biol Chem (2013) 288(34):24886-97. doi: 10.1074/jbc.M113.454835

115. Fukuda S, Kita S, Obata Y, Fujishima Y, Nagao H, Masuda S, et al. The Unique Prodomain of T-Cadherin Plays a Key Role in Adiponectin Binding With the Essential Extracellular Cadherin Repeats 1 and 2.J Biol Chem (2017) 292(19):7840-9. doi: 10.1074/jbc.M117.780734

116. Tanaka Y, Kita S, Nishizawa H, Fukuda S, Fujishima Y, Obata Y, et al. Adiponectin Promotes Muscle Regeneration Through Binding to TCadherin. Sci Rep (2019) 9(1):16. doi: 10.1038/s41598-018-37115-3

117. Fujishima Y, Maeda N, Matsuda K, Masuda S, Mori T, Fukuda S, et al. Adiponectin Association With T-Cadherin Protects Against Neointima Proliferation and Atherosclerosis. FASEB J (2017) 31(4):1571-83. doi: 10.1096/fj.201601064R

118. Fang Y, Wu N, Gan X, Yan W, Morrell JC, Gould SJ. Higher-Order Oligomerization Targets Plasma Membrane Proteins and HIV Gag to Exosomes. PLoS Biol (2007) 5(6):e158. doi: 10.1371/journal.pbio.0050158

119. Vidal M, Mangeat P, Hoekstra D. Aggregation Reroutes Molecules From a Recycling to a Vesicle-Mediated Secretion Pathway During Reticulocyte Maturation. J Cell Sci (1997) 110(Pt 16):1867-77. doi: 10.1242/ jcs.110.16.1867

120. Verweij FJ, Bebelman MP, Jimenez CR, Garcia-Vallejo JJ, Janssen H, Neefjes J, et al. Quantifying Exosome Secretion From Single Cells Reveals a Modulatory Role for GPCR Signaling. J Cell Biol (2018) 217(3):1129-42. doi: $10.1083 /$ jcb. 201703206

121. Hyenne V, Ghoroghi S, Collot M, Bons J, Follain G, Harlepp S, et al. Studying the Fate of Tumor Extracellular Vesicles at High Spatiotemporal Resolution Using the Zebrafish Embryo. Dev Cell (2019) 48(4):554-72.e557. doi: 10.1016/j.devcel.2019.01.014

122. Verweij FJ, Revenu C, Arras G, Dingli F, Loew D, Pegtel DM, et al. Live Tracking of Inter-Organ Communication by Endogenous Exosomes In Vivo. Dev Cell (2019) 48(4):573-89.e574. doi: 10.1016/j.devcel.2019.01.004

123. Sabaratnam R, Geertsen L, Skjodt K, Hojlund K, Dimke H, Lund L, et al. In Human Nephrectomy Specimens, the Kidney Level of Tubular Transport Proteins Does Not Correlate With Their Abundance in Urinary Extracellular Vesicles. Am J Physiol Renal Physiol (2019) 317(3):F560-71. doi: 10.1152/ ajprenal.00242.2019

Conflict of Interest: The authors declare that the research was conducted in the absence of any commercial or financial relationships that could be construed as a potential conflict of interest.

Publisher's Note: All claims expressed in this article are solely those of the authors and do not necessarily represent those of their affiliated organizations, or those of the publisher, the editors and the reviewers. Any product that may be evaluated in this article, or claim that may be made by its manufacturer, is not guaranteed or endorsed by the publisher.

Copyright (c) 2021 Sabaratnam and Svenningsen. This is an open-access article distributed under the terms of the Creative Commons Attribution License (CC BY). The use, distribution or reproduction in other forums is permitted, provided the original author(s) and the copyright owner(s) are credited and that the original publication in this journal is cited, in accordance with accepted academic practice. No use, distribution or reproduction is permitted which does not comply with these terms. 